\title{
Editor's Comment Re: Single-stage strategy for management of anterior table frontal sinus fractures involving the frontal sinus outflow tract
}

\author{
Ian T. Jackson
}

Received: 11 January 2011 / Accepted: 11 January 2011 /Published online: 21 May 2011

(C) Springer-Verlag 2011

The main reason why I accepted this paper was that, although some of us would deal with this problem, many plastic surgeons would not. There is no reason why plastic surgeons do not learn these techniques and apply them to the skull base area when indicated. This involves a good and secure neurosurgeon who finds this acceptable. The plastic surgeon should also be able to deal with skull base bleeding, dural tears, reconstructing base of skull bony defects, and the surgical management of sinus infection.
Even if the plastic surgeon rarely ever does any of these procedures, he or she should know the indications for using them. In this way, the combined neurosurgical and plastic surgical groups are more secure in the combined management in the skull base area.

There is good reason for having these in our journalwe need more of this type of presentation. I thank the authors for sending this paper to me. 